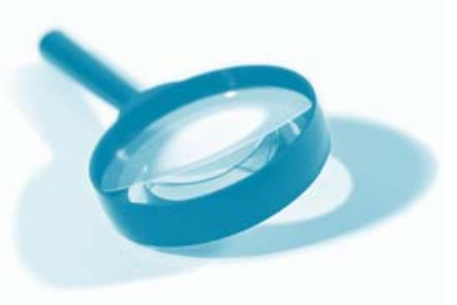

\title{
A blended-leaming approach to supporting students in organic chemistry: methodology and outcomes
}

\author{
Richard C D. Brown \\ Jeremy D Hinks and \\ David Read* \\ Faculty of Natural and \\ Environmental Sciences \\ (Chemistry) \\ University of Southampton \\ Highfield \\ Southampton SO17 1BJ \\ *d.read@soton.ac.uk
}

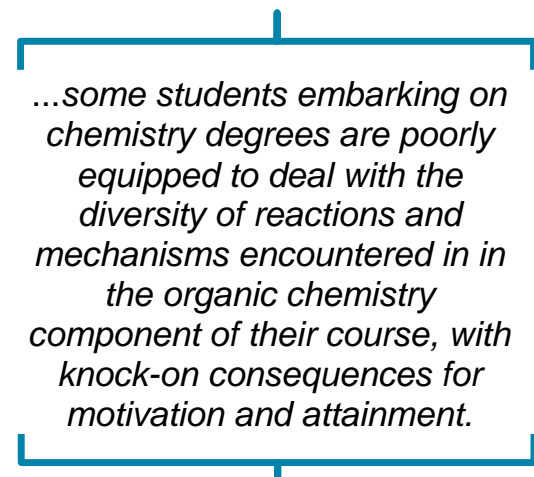

\begin{abstract}
In the recent past, we recognised the need to support students in developing an effective approach to learning mechanistic organic chemistry, as many were finding it challenging to identify appropriate strategies to tackle this key area of their studies. A set of supporting resources in the form of videos and animations to reinforce understanding of the basic principles behind mechanisms were designed to improve skill levels and confidence. An online approach to delivery and engagement was combined with selfassessment to produce a package that was delivered as a vacation activity which was not credit bearing.
\end{abstract}

The outcomes of the initial experiment included excellent levels of uptake by students, with many expressing greater confidence in their ability to understand and apply their mechanistic knowledge. Since the first iteration of this project a thorough qualitative evaluation has been undertaken. The clear message is that students found these resources valuable in their learning. This paper will describe the methodology and the outcomes from both the student and tutor perspective.

\section{Background}

It is clear that incoming undergraduates have variable skill levels in the area of mechanistic organic chemistry, having typically encountered fewer mechanisms at Alevel than in the past. ${ }^{1}$ The experiences of A-level teachers indicate that exam boards have become increasingly pernickety about the precision of the drawn representation of a mechanism, making the rote-learning of mechanisms both possible and attractive for some students. Indeed, some teachers will even rote-teach mechanisms, concentrating on the static diagram, preventing some students from developing any level of appreciation of the underlying principles. ${ }^{2}$ As a result, some students embarking on chemistry degrees are poorly equipped to deal with the diversity of reactions and mechanisms encountered in in the organic chemistry component of their course, with knock-on consequences for motivation and attainment. Recent research has shown that students of organic chemistry adopt a range of "positions along the continuum between meaningful learning and rote memorisation" when approaching their studies. ${ }^{3}$ As such, solutions to the problem of how to help students to truly 'get to the bottom' of organic chemistry remain both a goal and a significant challenge for educators.

\section{The rationale for our intervention}

Analysis of exam result data in January 2010 showed that a number of second year chemistry students were performing less favourably in organic chemistry than they were in inorganic and physical chemistry. In order to identify the reasons for the anomaly, a number of students were interviewed in two separate focus groups where they were able to express their views in a supportive environment. Many of the students indicated that they had enjoyed organic chemistry at school and were considered to be good at it, but they had found it difficult to translate this into success at degree level. Discussion with these students showed that they had become accustomed to learning the precise details of how to draw mechanisms, with curly arrows in particular being a focus for their attention. These individuals had attempted to rote-learn their way through first year organic chemistry, with varying degrees of success, but most were caught out by the leap in the volume of material, its complexity and the level of expectation that accompanied the transition to Year 2 of their studies. It was clear that those who were under-achieving in organic chemistry would benefit greatly from targeted support, with a view to maximising their future performance in the sub-discipline. 
There is a large body of research into the benefits of selfassessment and other types of formative assessment, much of it referring to the pioneering work of Wiliam and Black. ${ }^{4}$ The high profile of this research has led to formative assessment strategies being adopted widely by schoolteachers in the UK, and there is clear evidence that students benefit enormously from well-designed activities of this nature. ${ }^{5}$ There is anecdotal evidence that teaching staff in UK university chemistry departments are using formative assessment in a number of ways, but there is little in the way of published work in this area. ${ }^{6}$ We felt that the problems facing our students in developing a deeper understanding of organic reaction mechanisms were in part due to their inability to reflect effectively on their own work. Part of the rationale for introducing a component of self-assessment was our desire to 'force' students to reflect in a critical and constructive fashion in order to give them the confidence to be able to work out mechanisms from first principles instead of relying on memorisation. enter their marks for each question, and their total mark into the survey, which was delivered via our institutional virtual learning environment, Blackboard. In order to ensure that students reflected on their achievements, they were also required to answer a few questions about the outcomes of the exercise and what they would do to maximise their future performance. The survey data was collected and analysed as part of the evaluation process, as outlined in a subsequent section of this article.

\section{Video tutorials and mark schemes}

Video tutorials and mark schemes were created in the same format we had previously developed for presenting recorded lectures as online packages. ${ }^{7}$ It has been shown previously that students view shorter, more focussed clips favourably, with a 'vignette' format providing a bite-sized synopsis of the key information relating to a particular topic..$^{8}$ In view of the visual nature of organic chemistry, we decided to exploit the power of tablet PCs, as previously outlined by O'Malley. ${ }^{9}$

\begin{tabular}{|c|l|}
\hline \multicolumn{2}{|c|}{ Table 1: Timings of the different stages of the intervention. } \\
\hline \multicolumn{2}{|c|}{ Intervention/activity } \\
\hline $19-20$ & Focus groups with students to identify the nature of their difficulties with aspects of the course \\
\hline $22-25$ & Face-to-face tutorials \\
\hline $26-29$ & $\begin{array}{l}\text { - Video tutorials and pencasts made available } \\
\text { - Vacation exercise to be completed }\end{array}$ \\
\hline 30 & $\begin{array}{l}\text { - Vacation exercise handed in for checking } \\
\text { - Vacation exercise returned for students to complete self-assessment } \\
\text { - Video mark schemes and data-collection survey made available on Blackboard }\end{array}$ \\
\hline 31 & Deadline for completion of self-assessment exercise and survey \\
\hline $34-35$ & Examination period \\
\hline
\end{tabular}

\section{Methodology}

The intervention was based on blended-learning methodology and had a focus on developing organic chemistry skills. Some face-to-face teaching in the form of tutorial support was provided, but the main body of supporting material was placed online in the form of videos and related resources. At the core of the intervention was a traditional 'Problem Sheet', set in the form of an Easter Vacation Exercise, which was to be selfassessed by students once completed. The self-assessment process was supported by video mark schemes which gave students detailed guidance on how to construct viable answers to organic chemistry problems, as well as explaining the principles which underpin the use of mechanisms to illustrate our understanding of the progress of organic reactions.

Table 1 below outlines the different resources which were provided to students, and the timescales which were applied. Students were briefed at the start of the process to ensure that they knew what support was available and what was expected of them. The Easter Vacation Exercise was mandatory for all students achieving $<60 \%$ in the January exam and engagement in the self-assessment process among this cohort was checked by monitoring the completion of a survey. All students in the year group were invited to complete the activity, and a number of high achievers also took part. Students were required to
A more detailed description of the technical process used here has been reported previously. ${ }^{10}$ Figure 1 illustrates the screen layout used for these resources, with a talking head accompanying slides which are annotated in real-time by the tutor using the tablet PC. ${ }^{11}$ The resulting videos were made available to students via Blackboard. The content of the video tutorials was intended to support students in developing a better understanding of the fundamental aspects of organic chemistry that underpin the more advanced material they were currently covering in lectures. An emphasis was placed on the 'rules' which allow organic chemists to work out mechanisms and reaction outcomes from first principles without necessarily having prior knowledge of the reaction in question.

To complement the video tutorials, several 'pencasts' were created using a digital pen and paper. ${ }^{12} \mathrm{~A}$ pencast is an animated, narrated package which delivers similar content to a video tutorial. The pencast is created by the tutor in a one-step process, and the resulting file is uploaded to a server and made available for students to access online via a URL. This approach was trialled as a means of engaging staff who either lack technical expertise or the time to spend on the creation of videos on tablet PCs. However, a downside of this approach is that it isn't possible to edit the final product once uploaded to the server, which presents the serious challenge of needing to 


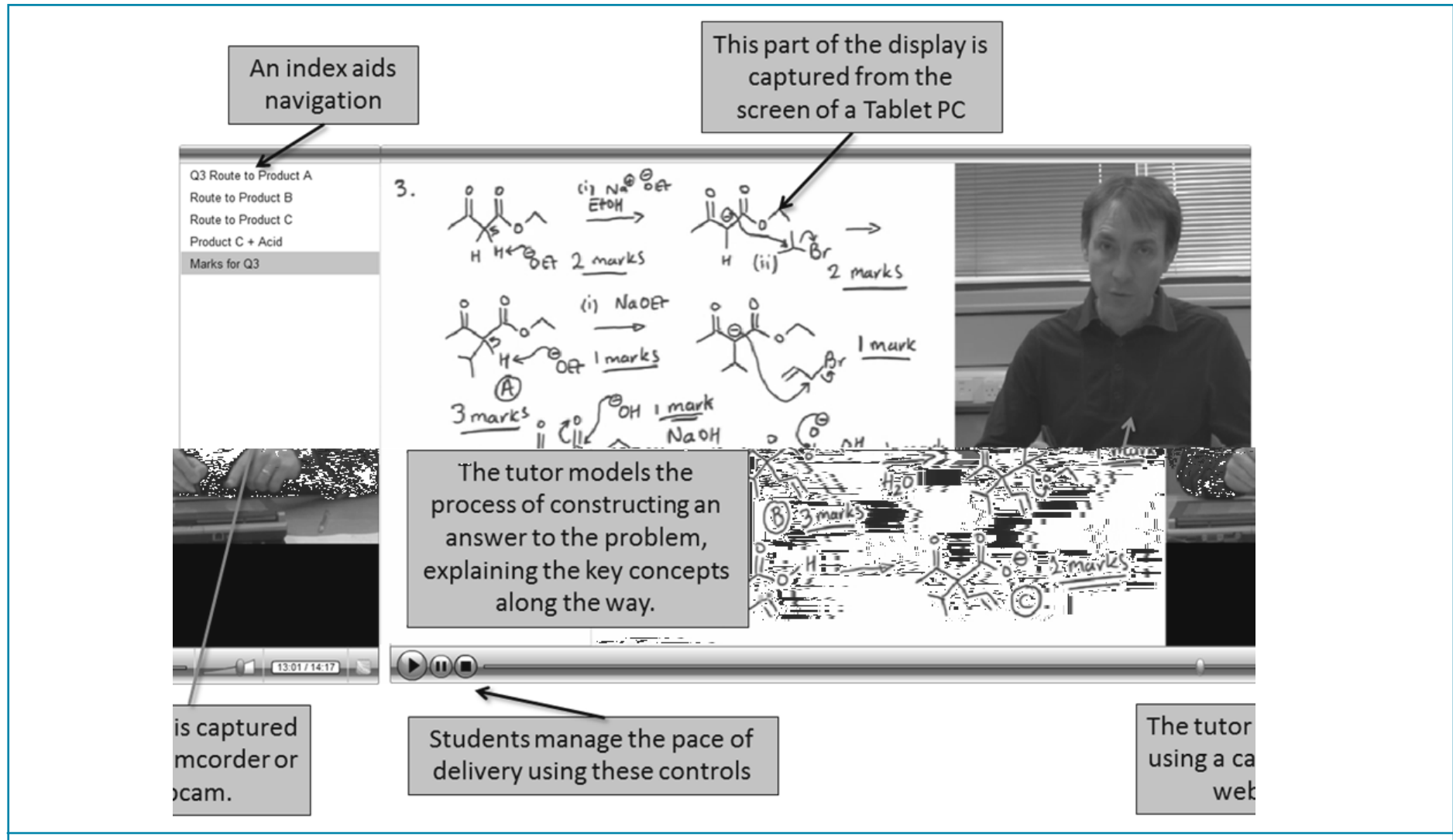

Figure 1: Screen layout for video tutorials and mark schemes.

do everything in one take. While it would be possible to use Camtasia to capture the pencast for editing, this would defeat the object of using the pencast approach, namely the technical simplicity of the process. Also, the sustainability of resources created and deployed in this way depends on the website of the host provider, with the risk of it being closed down at some point in the future. The pencasts created as part of this support package were complementary to the video tutorials in that they covered other aspects of elementary degree level organic chemistry with a focus on developing skills and confidence.

\section{The student response: feedback}

Statistics tracking within Blackboard showed that students made extensive use of the video tutorials and pencasts, most notably over the Easter vacation period and again in the run up to the June examination period. However, the volume of qualitative data collected from the Blackboard survey came as a surprise, with over 8000 words being submitted by the 57 students who completed the survey. ${ }^{13}$ Within this data are many valuable insights regarding the ways that students use such resources to support their learning, along with useful feedback on the quality and value of the resources provided.
As outlined previously, the first few questions in the survey asked the students to enter their marks for each question, along with an overall mark for the exercise. The remaining questions allowed students to enter a free-text response, and these were aimed at encouraging reflection and constructive feedback. Questions 1 and 2 (below) were designed to collect feedback from students regarding the value of the resources and the exercise.

Question 1: "How useful were the resources that we made available over the Easter? We need your feedback to help us decide if we should produce more of these resources."

Question 2: "Has this been a useful exercise for you? Please explain why you think this (whether you have a positive view or a negative one). We need your feedback so we can decide if we should do more of this sort of thing."

Table 2 illustrates a semi-quantitative analysis of the comments collected regarding the usefulness of the resources (Q1) and the self-assessment exercise itself (Q2).

Table 2: Semi-quantitative analysis of the responses to questions 1 and 2.

\begin{tabular}{|c|c|c|c|c|}
\hline Comment on usefulness: & $\begin{array}{c}\text { Very positive e.g. "very } \\
\text { useful", "excellent" }\end{array}$ & $\begin{array}{c}\text { Positive e.g. } \\
\text { "useful", "good" }\end{array}$ & Neutral e.g. "OK" & Negative \\
\hline $\begin{array}{c}\text { Occurrences in responses } \\
\text { to Q1 }\end{array}$ & 43 & 10 & 4 & 0 \\
\hline $\begin{array}{c}\text { Occurrences in responses } \\
\text { to Q2 }\end{array}$ & 27 & 27 & 2 & 1 \\
\hline
\end{tabular}


Many students gave detailed responses to questions 1 and 2, which give valuable insights into the value of these resources. A number of students commented on the value of the video tutorials and pencasts in terms of the way they helped to shed light on why reactions happen, and what curly arrows really represent. Some example quotes are given below:

"...it is good to be able to think about where the electrons are going rather than just trying to memorise arrow positions."

"...shows why the mechanisms happen... gives the required chemistry background to allow similar questions to be answered more easily"

“...explanation of the mechanisms...is invaluable in that we can also see the 'train of thought' we should practise in approaching mechanisms."

"Learning the method of approaching the mechanism is just as valuable as knowing the chemistry outright."

Many students also commented on the value of selfassessment exercises, with a particular focus on the importance of them identifying their own mistakes and weaknesses coupled with the guidance provided to help them make corrections. A few representative examples of such comments are given below:

“...see where you've gone wrong if you're marking it yourself rather than having a cross."

"I have been able to take the time to go through each mechanism and work out where I went wrong instead of just receiving a mark."

“...the reasons why (the mechanism) happened a certain way were explained so I understood more clearly what my mistakes were."

\section{The student response: reflection}

Questions 3 and 4 in the survey were intended to encourage the students to reflect on their overall performance in the exercise and to formulate a strategy to fulfil their potential in organic chemistry.

Question 3: "How do you feel about your performance on this exercise?"

Question 4: "What are you going to do to ensure that you maximise your performance in organic chemistry?"

Responses to question 3 showed that students had taken the exercise seriously, with a majority expressing some dissatisfaction with their performance. A number of the comments showed that students had lost marks for missing small details out, which completion of this exercise will help to prevent in future. Many students gave specific examples of questions which had been problematic, indicating that these were areas for improvement.
The responses to question 4 indicated that different students planned to adopt a range of different strategies, with most of them referring specifically to their plans for revision for the imminent June exams. Many students indicated that they would continue to use the new resources to support their studies, and there was much recognition of the importance of practising mechanisms in order to be able to work them out and recognise their key features. Although a significant number of students mentioned having to 'learn mechanisms', it was clear from other aspects of their feedback that most of these individuals were not referring simply to rote-learning.

\section{Conclusions}

It should be noted that our discussions with students indicated that the face-to-face tutorials had been useful in allowing them to ask questions and interact with academics. However, there was a clear indication that the real benefits of the intervention were derived from the online resources and the selfassessment exercise. It is clear from the feedback that most of the students completing this exercise made a great leap forward in their ability to reflect on their own performance, with an accompanying increase in confidence.

The feedback clearly indicates that there was increased awareness of the fact that the application of basic principles is a better way to approach organic chemistry than memorisation, and there is extensive evidence that many students have gained the confidence and skills needed to do this more effectively. Furthermore, the positive outlook indicated in much of the feedback indicates a re-engagement with organic chemistry which was reassuring for the staff involved.

As acknowledged previously, it is difficult to measure the educational impact of the intervention without a more thorough pedagogic investigation, but the volume and quality of feedback obtained from students gives some tantalising insights into the benefits of this approach. One final comment is worthy of consideration here:

"A brilliant exercise in covering things I had already understood, whilst simultaneously highlighting things I'd clearly managed to remember or even learnt wrong in the first place."

This comment shows that this particular student not only gained confidence from the exercise, but also identified and corrected some of their own misconceptions along the way. The value of self-assessment will vary from one individual to another, but it is clear that this is a student-centred approach with the potential to make a genuine and lasting impact those who engage thoroughly in the activity. 


\section{References}

1. Read, D. and Harrison, C. K. (2010) Review of A-level Chemistry Content. Downloadable from: $<$ www.edshare.soton.ac.uk/5853/> (accessed May $8^{\text {th }}$ 2012).

2. Bailey, $P$ (2007) School-to-university transition: comparison of the A-level chemistry specifications with year 1 at university, Royal Society of Chemistry (This was the final report from the Syllabus Group affiliated to the Chemistry for our Future Programme).

3. Grove, N. P. and Bretz, S. L. (2012) A continuum of learning: from rote memorization to meaningful learning in organic chemistry, Chemistry Education Research and Practice. Advance Article. DOI: 10.1039/C1RP90069B.

4. Black, P. \& Wiliam, D. (1998), Inside the Black Box: raising standards through classroom assessment, King's College, London.

5. For an example, see: Black, P. \& Harrison, C. (2001), Selfand peer-assessment and taking responsibility: the science student's role in formative assessment, School Science Review, 83, 43-49.

6. For an example, see: Bedford, S. \& Legg, S. (2007), Formative peer and self feedback as a catalyst for change within science teaching, Chemistry Education Research and Practice, 8, 80-92

7. Andrews, C. J., Brown, R. C., Harrison, C. K., Read, D. and Roach, P. L. (2010) Lecture capture: Early lessons learned and experiences shared, New Directions in the Teaching of Physical Sciences, 6, 56-60.

8. Lancaster, S. J. and Read, D. (2011) Screencasts and vignettes. Wavelength, 7, 40-41.

9. O'Malley, P. J., (2010) Combining a Tablet personal computer and screencasting for chemistry teaching, New Directions in the Teaching of Physical Sciences, 6, 64-67.

10. Read, D. and Duckmanton, P. (2012) Students writing their own feedback; self-assessment mediated by video mark schemes, Proceedings of HEA STEM Conference, Higher Education Academy, available online: <www.heacademy.ac.uk/stem-conference/landt2> (accessed 8th May 2012).

11. Slides are annotated within Powerpoint on a Tablet PC running Windows, using the software package Camtasia $<$ www.techsmith.com>

12. For these purposes a Livescribe pen and Anoto digital paper were used. See <www.livescribe.com/uk/> for details (accessed May $8^{\text {th }}$ 2012).

13. The complete collection of feedback and reflections is accessible here: $<$ www.edshare.soton.ac.uk/7596/> (accessed May $8^{\text {th }}$ 2012). 